\title{
WHO EXPERT COMMITTEE ON LEPROSY, 5TH REPORT*
}

The Reports of the WHO Expert Committee on Leprosy have been of the utmost importance to leprosy workers everywhere, offering an international concensus of expert experience and guidance on matters of current concern and practice. The Report of the Fifth Expert Committee, held at Geneva, 19-25 October, 1976, is no exception. Coming at a time of very rapid development in leprology and high international concern, it distils into a relatively few pages a great deal of up-to-date information, corporate wisdom, and sound judgement.

The Report is divided into 4 main sections: Epidemiology, Strategy of Leprosy Control; the Formation and Management of a Leprosy Control Programme; and Research.

The section on Epidemiology emphasizes the scale both of the leprosy problem itself and social and economic effects of physical handicaps caused by leprosy. The new evidence on the transmission of leprosy is presented very clearly. The relevance and usefulness of information collected in Leprosy Control Programmes and prevalence and incidence rates leads to the conclusion that by present methods a significant impact can be made on the transmission of the disease.

Section 2 on the Strategy of Leprosy Control presents the latest views on this subject and many useful points are brought out. The increasing occurrence of dapsone resistance leads to other important suggestions for combined therapy. Problems in the treatment of reactions also receive attention, as do relapses, prophylaxis by BCG and chemoprophylaxis.

Section 3 deals with the practice of Leprosy Control, and in particular with aims, objectives, integration of medical services and evaluation.

Section 4 gives an impressive list of recommendations for future research priorities.

This Repurt needs to be in the hands of every professional member of Health Ministries and Voluntary Agencies concerned with leprosy, and will be a vital source of reference for several $y^{\prime}$ ears to come.

.mid so much that is excellent, it is almost invidious to draw attention to one lack of emphasis in the Report. While there is reference to the need for Health Education in Urban Leprosy Schemes, the significance of leprosy as a social as much as a medical problem in general situations is not explnred as explicitly as could be wished. Leprosy Control Schemes may be models of medical ila ng and practice, but they stand or fall on the response of patients and the public, and this is a social not a medical issue, but one of great importance.

T. F. DAVEY

\footnotetext{
* World Health Organization Technical Report Series No. Geneva,
} 